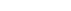

\section{The impact of reflective and permeable pavements on the urban microclimate}

\author{
Andrea Ferrari ${ }^{1}$, Aytac Kubilay ${ }^{2}$, Dominique Derome $^{2}$, J. Carmeliet ${ }^{1}$ \\ ${ }^{1}$ Chair of Building Physics, Swiss Federal Institute of Technology, \\ ETHZ, Zurich, Switzerland \\ ${ }^{2}$ Laboratory of Multiscale Studies in Building Physics, Swiss Federal Laboratories for \\ Material Science and Technology (Empa), Dübendorf, Switzerland
}

\begin{abstract}
The impact of reflective and permeable pavements on the urban microclimate is investigated in this study by means of a fully-integrated urban microclimate model, which couples the transport of heat and moisture in the air and the building materials as well as the solar and thermal radiative exchange between urban surfaces and the sky. The proposed approach yields detailed analysis of the impact of different types of pavement materials on the absorption and storage of heat and moisture in urban environments. The case study of an isolated street canyon shows limited evaporative cooling potential and decreased thermal comfort conditions for conventional impervious pavements and dark-colored surfaces compared to porous pavements and high reflective materials.
\end{abstract}

\section{Introduction}

The increase in urban heat island (UHI) effect has disadvantages on thermal comfort and health as well as on building energy consumption, air quality and greenhouse gas emissions (Moonen et al., 2012). Pavements including roads, sidewalks and parking areas, cover a large fraction of urban areas and contribute significantly to UHI development (Akbari et al., 2001; Ferguson, 2005). The thermal balance of urban surfaces is determined by the amount of solar radiation absorbed, the thermal radiation emitted, the heat loss by convection to the air and the heat stored and conducted into the ground. When wet, latent heat must be taken into account as well, since water evaporation from the pavements may cool down the surface by evaporative cooling. However, most of the existing pavements consist of impervious, dark-colored materials, such as conventional asphalt and concrete, which decrease evapotranspiration in urban areas and increase sensible heat storage and absorption of solar radiation due to the use of lowalbedo materials.

Among different mitigation measures proposed with the aim of decreasing the UHI effect, a promising strategy involves the use of the so-called cool pavements, which are able to reduce their surface temperature by either increasing solar reflections or through evaporative cooling. According to Santamouris (2013), cool pavements can be divided in two main categories: reflective pavements that combine high solar reflectivity with high emissivity to dissipate solar radiation and permeable or water retentive pavements that use the latent heat of vaporization to reduce their surface temperature.

In order to assess the ability of the combined strategies of reflective and permeable pavements to be used as possible mitigation measures for local urban heat islands, it is essential to be able to predict the urban microclimate. Field measurements and lab scale experiments can provide significant information on the thermal (Akbari et al., 2001; Carnielo and Zinzi, 2013) and hydric (Kevern et al., 2009; Li et al., 2013) behavior of cool pavements. However, such measurements are typically time-consuming and document only the local and instantaneous meteorological conditions taking place during the measurement. On the other hand, numerical simulations based on Computational Fluid Dynamic (CFD) can resolve local effects and provide detailed information on the spatial and temporal distribution of temperature, humidity and wind speed.

In the present study a fully integrated microclimate model is employed to evaluate the potential cooling effects of reflective and permeable pavements in urban environments. The model couples different physical phenomena including turbulent and buoyant wind flow around buildings, heat and moisture transport in the air and in the porous building materials and the radiation exchange between the urban surfaces and the sky. It allows for a detailed spatial analysis of different cooling mechanisms such as shading, cooling due to increased reflectivity, convective and evaporative cooling and their impact on thermal comfort. For this case study an isolated street canyon is considered under dry and wet conditions. Three permeable pavements presenting different porosities and hydraulic properties are considered and their thermal performances and evaporative cooling potentials are investigated in comparison to standard pavement systems. The surface albedo of the street is varied and the influence of both absorbed and reflected radiation 
on air temperature and thermal comfort is analyzed.

\section{Methods}

The microclimate model couples three submodels: (i) a CFD model, which solves turbulent, convective heat, air and moisture transport in the air domain; (ii) a Building-Envelope Heat-Air-Moisture (BE-HAM) model, which solves heat and moisture transport in the building materials and pavement; and (iii) a radiation model, which computes the solar and thermal radiative heat exchange between the urban surfaces and with the sky. The microclimate model is then supplemented with a comfort model to compute the thermal comfort conditions in the street canyon at pedestrian height. A detailed description of the full model can be found in Kubilay et al. (2018) and Defraeye (2011). In the reminder of this section, the three sub-models and the coupling strategy are briefly reviewed. To avoid abstraction, the description focuses on the three-dimensional street canyon used in the case study, but it is evident that more realistic urban geometries could as well have been investigated with the present model.

\section{CFD model}

We focus on a street canyon, composed of two long buildings with a south-north orientation. Buildings have dimensions of height $\times$ length $\times$ width of $10 \times 10 \times$ $50 \mathrm{~m}^{3}$, while the total domain has dimensions $60 \times$ $230 \times 250 \mathrm{~m}^{3}$. The wind direction is from west to east, perpendicular to the street canyon. A sketch of the computational domain showing the buildings orientation with respect to the wind direction and the sun position is given in Figure 1.

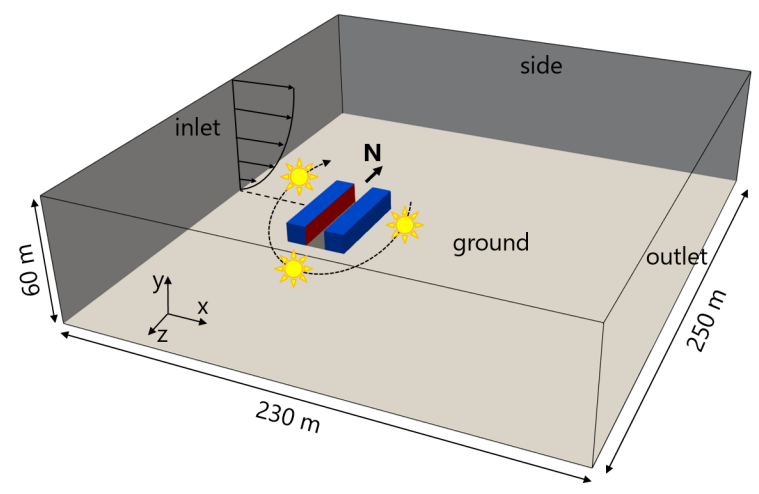

Figure 1: Computational domain and street canyon orientation with respect to the sun position and the wind direction.

As a compromise between computational cost and accuracy, we select a RANS (Reynolds-Average NavierStokes) approach for solving the turbulent wind flow in the street canyon. The standard $\kappa-\epsilon$ model is used for turbulence (Launder and Sharma, 1974) and additional equations for heat (as an active scalar) and moisture (as a passive scalar) are solved in the air domain. Mass, momentum and energy conservation equations are written in a compressible formulation, where density variations and buoyancy effects are directly taken into account by an equation of state, instead of using the Boussinesq approximation.

At the inlet of the domain, vertical profiles of the mean horizontal wind speed $(U)$, turbulent kinetic energy $(\kappa)$ and dissipation rate $(\epsilon)$ are imposed, representing a fully-developed atmospheric boundary layer over homogeneous terrain (see Kubilay et al. (2018)). A wall function for rough wall is used for the ground surface, representing a leveled country with low vegetation, while all the other street canyon surfaces are assumed to be smooth and modeled using standard wall functions. A constant static atmospheric pressure is imposed at the outlet.

\section{BE-HAM model}

Heat and moisture transport in the porous building materials are simulated using the BE-HAM models, which solves temperature and moisture transport equations for porous media, using a continuum (macroscopic) approach. A detailed description of the model and the governing equations is given in Defraeye (2011). It is important to note that latent heat due to phase change and enthalpy transport due to vapor diffusion are explicitly taken into account by the model.

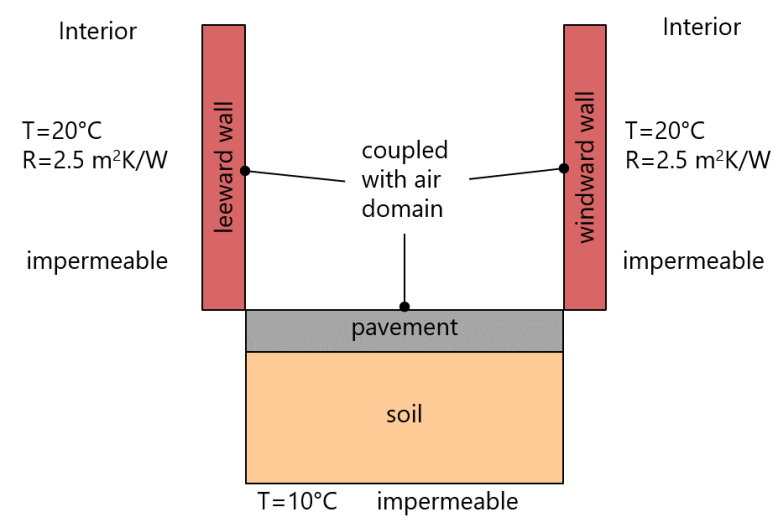

Figure 2: Computational domain for the street, the windward wall and leeward wall (not to scale).

The porous domain consists of three separated regions, namely the street, the windward wall and the leeward wall. All other surfaces are assumed to be impermeable and adiabatic (the ground, the roofs and lateral street canyon surfaces). A sketch of the porous solid domain is given in Figure 2. The following flux boundary conditions are set at the exterior surfaces of the porous building materials within the street canyon and at the top surface of the pavement:

$$
\begin{gathered}
g_{\text {ext }}=g_{c o n v} \\
q_{e x t}=q_{c o n v}+q_{r a d}+\left(c_{p, v} T_{s}+L_{v}\right) g_{c o n v}
\end{gathered}
$$


where $g_{\text {ext }}\left[\mathrm{kg} / \mathrm{m}^{2} \mathrm{~s}\right]$ is the total mass flux in the porous domain, $g_{\text {conv }}\left[\mathrm{kg} / \mathrm{m}^{2} \mathrm{~s}\right]$ is the total mass flux in the air domain, here caused by evaporation, and $q_{e x t}\left[\mathrm{~W} / \mathrm{m}^{2}\right]$ is the total heat flux, consisting of a convective component, $q_{c o n v}\left[\mathrm{~W} / \mathrm{m}^{2}\right]$, a combined shortand long-wave radiation component, $q_{r a d}\left[\mathrm{~W} / \mathrm{m}^{2}\right]$, and a latent and sensible component due to vapor exchange. The latter accounts for changes in sensible heat, where $c_{p, v}$ is the specific heat capacity of water vapor $(1880 \mathrm{~J} / \mathrm{kgK})$, and for phase change via the latent heat of vaporization, $L_{v}\left(2.5 \times 10^{6} \mathrm{~J} / \mathrm{kg}\right)$. $T_{s}$ is the absolute temperature on the surface. Note that the convective mass and heat fluxes are obtained in the CFD calculation.

\section{Radiation model}

The radiation model solves the net radiative heat exchange (short-wave and long-wave radiation) between the street canyon surfaces and the sky, based on a radiosity approach. Air is considered as a non-participating medium, thus absorption, scattering and emission of radiation by air is neglected. The model further assumes that all surfaces are opaque to both solar and thermal radiation and that they are gray and diffuse, i.e. emissivity and absorptivity are equal and independent of wavelength and direction. Reflections are assumed to be diffuse, and multiple reflections between surfaces are calculated using view factors. The model output is the combined (shortand long-wave) net radiative flux, $q_{\text {rad }}$, for each surface involved in the radiation exchange (street, leeward and windward walls). The derivation of $q_{r a d}$ is given in Kubilay et al. (2018).

\section{Solver settings and coupling strategy}

The three sub-models (CFD, BE-HAM and radiation) are implemented in OpenFOAM 2.4. The coupling between the air and the porous domain is performed by sequentially solving the steady governing equations in the air domain and the unsteady governing equations in the solid domain for each exchange time step in a daily cycle of ambient temperature and relative humidity. The exchange time step is defined as the time at which information are exchanged at the boundaries and it is set here to 10 minutes based on previous studies (Saneinejad et al., 2014; Kubilay et al., 2018). Since the time scale of transport in the air domain is smaller than that in the building materials, it is assumed that the solution of the air domain remains constant during the transient simulation in the porous domain.

For each exchange time-step, first, the steady air flow is solved. The SIMPLE algorithm (Ferziger and Peric, 2012) is employed for pressure-velocity coupling. Second order discretization schemes are used for both the convective and viscous terms. At the boundaries between the air and the porous domains a fixed temperature and a fixed relative humidity are specified, whose values correspond to those in the solid domain. The simulation in the air domain is continued until all normalized residuals fall below specified tolerances: $10^{-5}$ for velocity, pressure and turbulent quantities, and $10^{-4}$ for heat and moisture. Afterwards, the calculated heat and moisture fluxes in the air domain are applied as boundary conditions for solving the transient heat and moisture equations in the porous domain. The simulation is performed using an iterative procedure and adaptive time-step, in which the thermal radiative fluxes are updated until temperature and moisture content values converge. Finally the new values for temperature and moisture content at the boundaries are used to solve the steady air flow for the next exchange time-step.

\section{BE-HAM model validation}

Since the CFD model for the air domain uses a quite standard approach for simulating turbulent flow around buildings and limitations are known $(\mathrm{Mu}-$ rakami, 1993), here we only present the validation of the BE-HAM model, which is essential to properly account for the drying of porous pavements. A full validation of the coupled model is not easy to perform using standard experimental techniques, since it would require the simultaneous monitoring of the air flow and the moisture transport in the porous material, as well as a complete knowledge of the material properties. Therefore, it is left for future work.

The BE-HAM model is compared with the HAMSTAD benchmark cases $n^{\circ} 5$ (Hagentoft et al., 2004), which deals with the moisture redistribution inside a wall with capillary active interior insulation. The wall consists of three layers: brick (365 mm), mortar (15 $\mathrm{mm})$ and insulating material $(40 \mathrm{~mm})$. The structure is airtight. Initial temperature and moisture content are both constant all over the wall $\left(25^{\circ} \mathrm{C}\right.$ and $60 \%$ relative humidity). At time zero there is a sudden change in temperature and vapour pressure at both the interior $\left(20^{\circ} \mathrm{C}\right.$ and $60 \%$ relative humidity) and exterior $\left(0^{\circ} \mathrm{C}\right.$ and $80 \%$ relative humidity) side. The simulation time is 60 days. The $1 \mathrm{D}$ wall is discretized with 185 hexahedral cells ( 150 in the brick, 15 in the mortal and 20 in the insulating material), gradually refined towards the boundaries.

Figure 3 shows the relative humidity distribution inside the wall after 60 days. The comparison between our results and the reference solution extracted from Hagentoft et al. (2004) shows a good agreement and validates the BE-HAM model.

\section{Description of the case study}

The case study considers the microclimate conditions in an isolated street canyon (see Figure 1) on a typical summer day. The reference wind speed at the building height is $3 \mathrm{~m} / \mathrm{s}$. The meteorological data are based on a typical day of the year (Meteonorm, 2000 ) and the total solar radiation intensity for a clear 


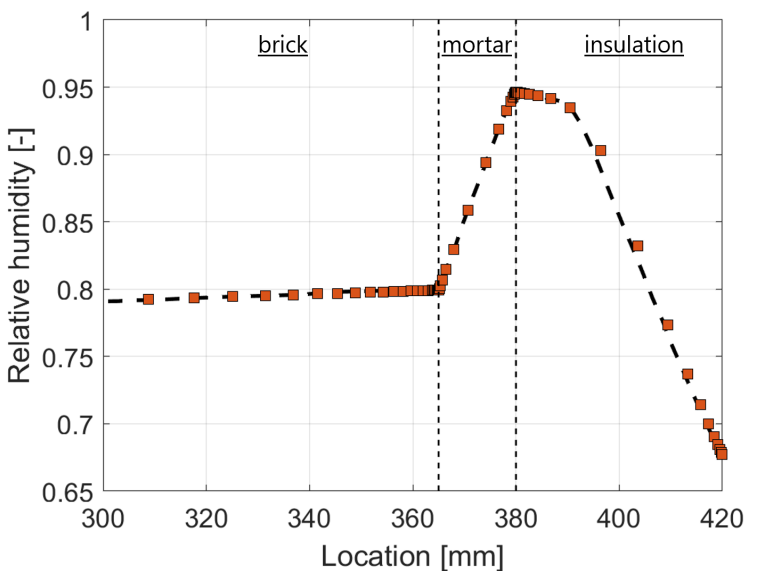

Figure 3: Relative humidity distribution inside the wall after 60 days. The dashed line is the reference solution extracted from Hagentoft et al. (2004), while orange squares are results from the current BE-HAM model.

sky (ASHRAE, 2001) for 21st of June in the city of Zurich, Switzerland. The ambient temperature oscillates between $11^{\circ} \mathrm{C}$ and $19^{\circ} \mathrm{C}$, while the relative humidity varies between $62 \%$ and $86 \%$ (see Kubilay et al. (2018) for further details).

The leeward and windward wall of the street canyon are finished with $0.09 \mathrm{~m}$ of clay brick. The interior surfaces are assumed to be impermeable and modeled with a thermal resistance of $2.5 \mathrm{~m}^{2} \mathrm{~K} / W$. An indoor temperature of $20^{\circ} \mathrm{C}$ is assumed (see Figure 2). An emissivity of 0.9 and an albedo of 0.4 is selected for the outer surface of the facades, for all street configurations. The street consists of an outer $0.15 \mathrm{~m}$ layer of pavement, below which soil with a depth of $1.9 \mathrm{~m}$ is located (soil properties are taken from Hagentoft et al. (2004)). The bottom of the soil layer is assumed to be impermeable and at constant temperature equal to $10^{\circ} \mathrm{C}$.

In order to assess the impact of cool pavements on the urban microclimate, permeable and reflective materials having different hydraulic and thermal properties are considered for the pavement layer. Permeable pavements, such as porous asphalt or porous concrete, include additional voids compared to the corresponding dense materials, thus having higher porosity and smaller heat capacity and thermal conductivity. Porosity of permeable pavements typically ranges between $10 \%$ and $30 \%$ and the saturated liquid permeability is reported between $5 \times 10^{-5}$ and $4 \times 10^{-3} s$ (Santamouris, 2013; Fwa et al., 2015; Ferguson, 2005). These values are significantly larger than those of conventional dense pavements, whose porosity is typically lower than $10 \%$ and the liquid permeability is several orders of magnitude smaller. In order to reproduce the hydraulic properties of permeable pavements three target porosity are selected, namely 10\% (PA1), 20\% (PA2) and 30\% (PA3). For each target porosity, the material dry density, $\rho_{s}$, is evaluated from porosity as:

$$
\rho_{s}=(1-\psi) \rho_{s, c}
$$

where $\psi$ is the porosity and $\rho_{s, c}=2200 \mathrm{~kg} / \mathrm{m}^{3}$ is a nominal density for conventional asphalt concrete taken from Hagentoft et al. (2004). The saturated liquid permeability, $K_{s}$, is extracted from Fwa et al. (2015), who measured the liquid permeability of different porous asphalts. The thermal conductivity, which is a function of water content, is evaluated based on a simple model by assuming that an effective thermal conductivity can be written as the sum of the thermal conductivities of the three components of the porous material (solid, water and air):

$$
\lambda_{s}=(1-\psi) \lambda_{s, c}+\psi S_{l} \lambda_{l}+\psi\left(1-S_{l}\right) \lambda_{a}
$$

where $\lambda_{s, c}$ is the thermal conductivity of conventional dense concrete taken from Hagentoft et al. (2004), $\lambda_{l}=0.6 \mathrm{~W} / \mathrm{mK}$ is the water thermal conductivity, $\lambda_{a}=0.026 \mathrm{~W} / \mathrm{mK}$ is thermal conductivity of dry air and $S_{l} \simeq w / \psi \rho_{l}$ is the liquid saturation, being $w$ the water content and $\rho_{l}$ the water density. The heat capacity of the dry material, $c_{p, s}$, is derived as a function of porosity by fitting linearly the data reported by Hassn et al. (2016). Note that the heat capacity varies less with porosity compared to density and thermal conductivity. The water content and the unsaturated liquid permeability are assumed to be a function of capillary pressure only. The shape of the water retention curves is evaluated using the Van Genuchten model (Van Genuchten, 1980). The Van Genuchten coefficients are estimated from typical pore-size distribution of porous pavements reported in other experimental and numerical investigations (Brunetti et al., 2016; Fwa et al., 2015). In particular the capillary entry pressure, which determines the shape of the water retention curve, is estimated by assuming a maximum aggregate size, $d_{\max }$, ranging from $0.2 \mathrm{~mm}$ for PA1 to $3 \mathrm{~mm}$ for PA3, while the coefficient related to the width of the pore-size distribution is taken constant and equal to 1.6, in the range reported by Brunetti et al. (2016). The drying behavior of porous pavements is compared to that of conventional concrete, whose properties are extracted from Hagentoft et al. (2004). The hydraulic and thermal properties of the different materials used in this study are reported in Table 1, while the water retention curves and water permeabilities obtained from the Van Genuchten model are shown in Figure 4.

The pavement albedo $(\alpha)$ is determined by the color of its surface and its roughness. Typical values range from $\alpha<0.1$ for conventional near-black surfaces to $0.5-0.6$ for lighter colored materials (Carnielo and Zinzi, 2013; Santamouris, 2013). The role of albedo 
Table 1: Hydraulic and thermal properties of porous materials used in the case study. Concrete properties are taken from Hagentoft et al. (2004). $d_{\text {max }}$ represents the maximum aggregate size used to estimate Van Genuchten coefficients and $w$ the moisture content.

\begin{tabular}{cccccccc}
\hline & $\boldsymbol{\psi}$ & $\boldsymbol{\rho}_{\boldsymbol{s}}$ & $\boldsymbol{\lambda}_{\boldsymbol{s}}$ & $\boldsymbol{c}_{\boldsymbol{p}, \boldsymbol{s}}$ & $\boldsymbol{K}_{\boldsymbol{s}}$ & $\boldsymbol{d}_{\max }$ & $\boldsymbol{\alpha}$ \\
& {$[-]$} & {$\left[\mathrm{kg} / \mathrm{m}^{3}\right]$} & {$[\mathrm{W} / \mathrm{mK}]$} & {$[\mathrm{J} / \mathrm{kgK}]$} & {$[\mathrm{s}]$} & {$[\mathrm{mm}]$} & {$[-]$} \\
\hline Concrete & - & 2200 & $1.5+0.0158 w$ & 830 & $1.6 \cdot 10^{-15}$ & $2 \cdot 10^{-5}$ & $0.2($ case 1$)$ \\
\hline PA1 & $10 \%$ & 1980 & $1.35+0.0006 w$ & 820 & $1.133 \cdot 10^{-4}$ & 0.2 & $0.2($ case 2) \\
\hline & & & & & & & $0.2($ case 3) \\
PA2 & $20 \%$ & 1760 & $1.21+0.0006 w$ & 810 & $4.163 \cdot 10^{-4}$ & 0.75 & $\begin{array}{c}0.4(\text { case } 5) \\
0.6(\text { case } 6)\end{array}$ \\
\hline PA3 & $30 \%$ & 1540 & $1.06+0.0006 w$ & 800 & $1.536 \cdot 10^{-3}$ & 3 & $0.2($ case 4) \\
\hline
\end{tabular}
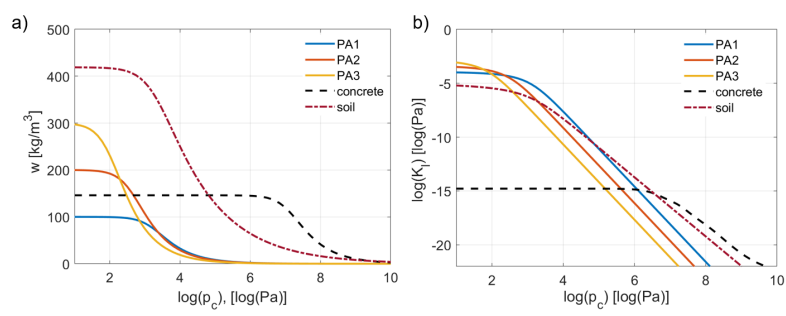

Figure 4: a) Water retention curves and b) liquid permeabilities for materials used in the case study.

is investigated by varying the reflectivity of the outer layer surface of the street.

Six different set of pavements properties are considered. In the first configuration that represent the base case, the pavement layer is considered as dense, conventional concrete, which is chosen as it has very limited moisture absorption in comparison to porous pavements. In cases 2,3 and 4 the $15 \mathrm{~cm}$ of the pavement layer are composed by PA1, PA2 or PA3, respectively. For each of these four configurations, the outer surface of the street has an emissivity of 0.9 and an albedo of 0.2 , representative of a dark-colored material. The effects of albedo are investigated in cases 5 and 6 , in which the reflectivity of the outer layer surface is varied between 0.4 (case 5) and 0.6 (case 6), keeping the emissivity constant and equal to 0.9 . For cases 5 and 6 the pavement material is PA2, i.e. the same as case 3 . The overview of all simulations is given in Table 1.

Initially all surfaces of the street canyon are assumed to be dry. For each street configuration, an initial simulation is run for several days using the climate data of the 21st of June, until the conditions in the street canyon reach a daily thermal cycle that is independent from the initial conditions. After this initial period, the pavement layer suddenly becomes $60 \%$ saturated with moisture (the soil layer is assumed to be $\sim 100 \%$ saturated), e.g. by a rain event or by deliberate wetting. This is modeled by assigning the pavement a capillary pressure that is representative of a $60 \%$ capillary saturated material. The wet simulation is then run from midnight of the first day (00:00) and continued for 2 days. Results obtained from the wet simulations are compared with those corresponding to a dry day.

\section{Results}

Figure 5 shows the variation of the average temperature and relative humidity (wet simulations) on the street surface for cases 1-4. When a wet porous material is drying, two different stages can be identified. During the first drying stage, the material cools down maximally due to evaporative cooling. During this period, the liquid transport from the inside of the material to the surface is fast enough to maintain the surface wet and at a relative humidity of approximately $100 \%$. When the surface dries out, the dry outer layer of the porous material forms an additional resistance to vapor diffusion and the drying rate starts to decrease. This stage is called the second drying period and it is marked by a drop in relative humidity below $100 \%$ and by an increase in surface temperature, since less heat is needed for water evaporation. It is evident that the longer the first drying stage is, the longer the surface is cooled down by evaporative cooling.

The duration of the first drying phase is mainly determined by the material properties, which control liquid transport towards the surface. Due to its very limited water absorption properties, conventional concrete enters the second drying stage almost immediately after the start of the wet simulation (less than 10 minutes). Due to this reason, the impact of evaporation when peak temperature occurs, i.e the average temperature difference with respect to the dry case, is only about $4^{\circ} \mathrm{C}$ (note that dry temperatures are not shown in Figure 5). On the other hand, porous pavements undergo a much longer first drying phase with the cooling efficiency increasing with decreasing pavement porosity. PA3 (case 4) enters the second drying phase (marked by a drop in relative humidity below 100\%) after about nine hours, PA2 after approximately 10 hours, while PA1 remains in the first 


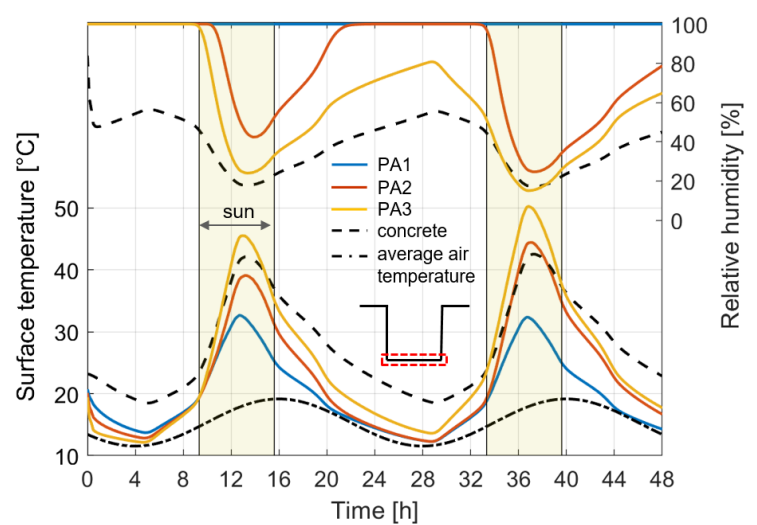

Figure 5: Variation of the average surface temperature and relative humidity on the street for the wet simulations (cases 1-4). The yellow band indicates when the street is exposed to direct solar radiation.

drying phase for the entire simulation period. The maximum cooling effect due to evaporation during the first day of drying is about $18^{\circ} \mathrm{C}$ for PA1 and reduces to $8^{\circ} \mathrm{C}$ for PA3. The latter shows the largest cooling efficiency in the first four hours of simulations, since it holds more water compared to the lower porosity pavements, thus also resulting in more evaporation. Concrete shows slightly smaller temperature during the second day of drying with respect to PA2 and PA3, which already entered the second drying phase, because of its larger thermal diffusivity. Even though PA1 can store less water compared to PA2 and PA3, it shows a larger temperature difference and a larger evaporation rate due to its finer pores, which can sustain liquid transport at the surface for longer times. On the other hand, liquid transport at the surface is limited in coarser materials due to gravity effects, reducing the evaporation rate and the consequent cooling efficiency.

The decrease in surface temperature is accompanied by a decrease in the air temperature in the street canyon. The air temperature variations are analyzed in terms of the thermal comfort of a human in the street canyon by assessing the Universal Thermal Climate Index (UTCI). The UTCI is expressed as the air temperature of a reference environment causing the same physiological responses as actual conditions (Fiala et al., 2012). The UTCI depends on four variables, namely the local air temperature, the vapor pressure, the wind speed and the mean radiant temperature, which is defined as the combined effect of the long-wave radiation and the short-wave radiation received by a person (see, for example, Saneinejad et al. (2014)). The thermal comfort for a person standing at the pedestrian height of $1.7 \mathrm{~m}$ in the center of the street canyon is shown in Figure 6 in the terms of the difference between the wet and dry case. The UTCI variations follow the surface tem-

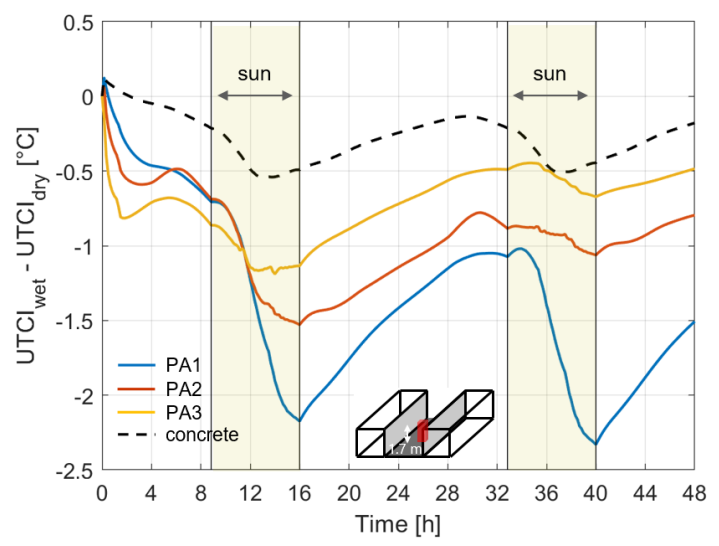

Figure 6: Variation of the UTCI difference between wet and dry simulations for cases 1-4.

perature variations. When the drying starts, better comfort conditions are observed for the PA3 configuration due to the larger amount of water stored in the pavement and the consequent larger evaporation rate and lower surface temperature. However in the longterm, a person standing in the middle of the street canyon would feel up to $2^{\circ} \mathrm{C}$ cooler with respect to the dry case if the PA1 configuration is used as pavement due to the increased duration of the first drying phase. Note that the effectiveness of evaporative cooling in creating more comfortable conditions in urban areas is limited, since the better comfort resulting from lower surface temperatures is partially canceled out by the higher relative humidity in the air due to evaporation. From Figure 6 it is evident that the beneficial effects are larger than the negative effects for all configurations, which implies that evaporative cooling resulting from permeable pavements can be more efficiently used to reduce urban temperatures and increase the urban comfort than that resulting from conventional pavements.

Figure 7 shows the variation of the average surface temperature and relative humidity of the pavement surface for cases 3-5-6. The increased solar reflectance further extend the duration of the first drying phase to 11-hours for $\alpha=0.4$ (case 5) and 13.5-hours for for $\alpha=0.6$ (case 6 ). This is because materials having lower albedo absorb more heat, which is then used for water evaporation, shortening the first drying period. When peak temperature occurs (around 13-hours), the combined effect of a lower dry temperature and a longer first drying phase results in a further decrease of surface temperatures of about $7^{\circ} \mathrm{C}$ for case 5 and $13^{\circ} \mathrm{C}$ for case 6 , compared to case 3 . Note that, although a lighter colored material absorbs less heat and exhibits lower surface temperatures, it also results in less evaporation from the surface and in smaller drop of surface temperature due to evaporative cooling. In fact, the maximum potential cooling 


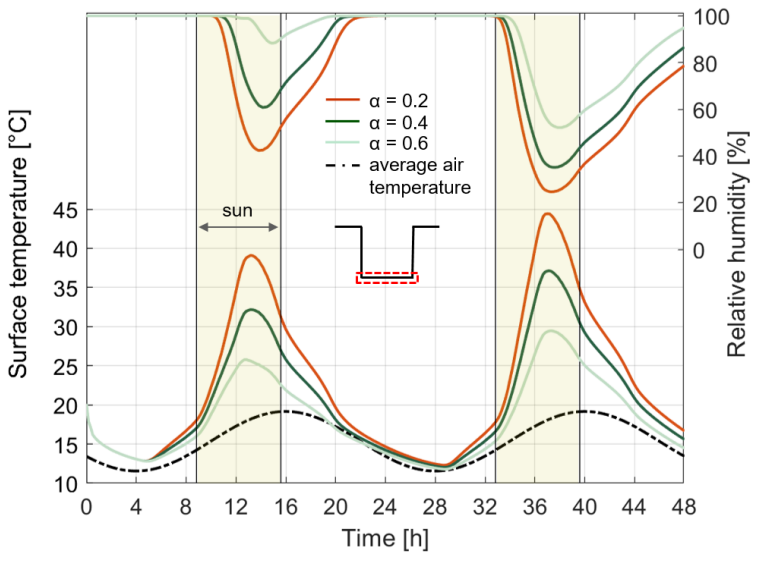

Figure 7: Variation of the average surface temperature and relative humidity on the street for the wet simulations (cases 3-5-6).

due to evaporation, i.e. maximum temperature difference between wet and dry case, reduces by about $1^{\circ} \mathrm{C}$ for case 5 and $2^{\circ} \mathrm{C}$ for case 6 , compared to the darkest colored case (case 3 ).

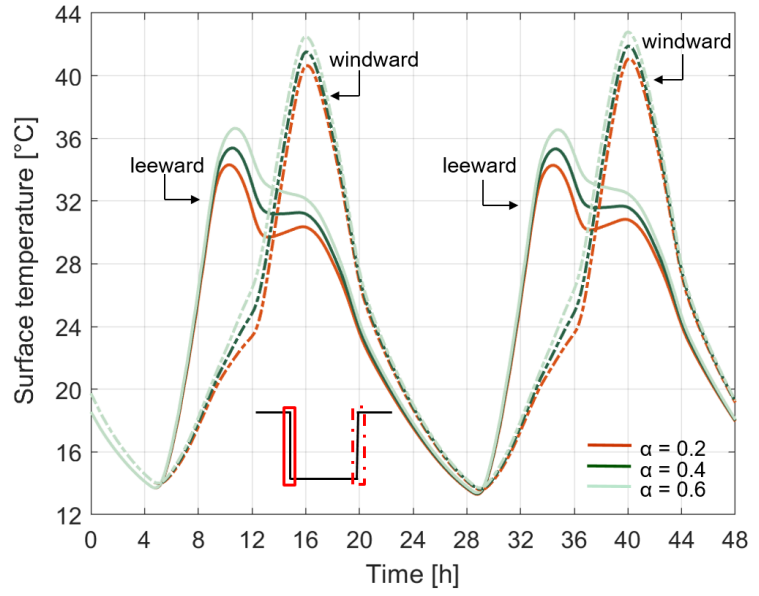

Figure 8: Variation of the average surface temperature on the leeward and windward walls for the wet simulations (cases 3-5-6).

Figure 8 shows the variation of the average surface temperature and relative humidity on the leeward and windward walls for cases 3-5-6. It is evident that temperatures slightly increase for increasing street albedo values. This is because the increased albedo also results in increased reflections from the street surface to the other surfaces, thus resulting in more solar radiation absorbed at leeward and windward facades. However, the increase in surface temperature on the leeward and windward walls $\left(1-3^{\circ} \mathrm{C}\right)$ are smaller compared to the decrease observed on the pavement surface. In fact, the increased solar reflections from the street surface for higher albedo values are partially compensated by the lower street temperatures, which result in lower thermal (long-wave) radiation emitted towards the other surfaces and lower air temper- atures.

In order to evaluate the impact of reflective pavements on the air temperature and thermal comfort, the UTCI is calculated for a person standing in the center of the street canyon. Figure 9 shows the variations of the UTCI difference between case 5 and case 3 and between case 6 and case 3 , to highlight the increased thermal comfort achieved by higher albedo pavements.

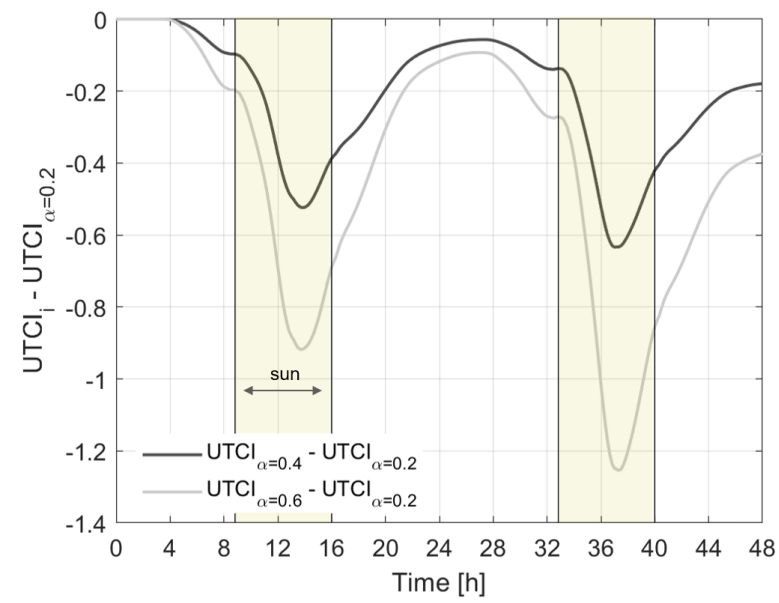

Figure 9: Variation of the UTCI difference between case 5 and case 3 and between case 6 and case 3.

Although the evaporative cooling potential decreases for increasing albedo values, our results show that the cooling provided by higher albedo pavements is large enough to guarantee lower surface temperatures, lower UTCI values and higher comfort conditions in the street canyon. However, attention must be paid for more complex urban geometries, since the increased reflections due to the higher albedo of the street surface may also finally result in higher air temperatures and reduced comfort conditions.

\section{Conclusion}

In this study, a fully integrated 3D numerical model is employed to investigate the impact of permeable and reflective pavements on the urban microclimate. Turbulent wind flow around buildings including heat and moisture transport is solved in the air domain and it is coupled with heat and moisture transport in the porous buildings materials (pavement and facades). The model is able to provide detailed spatial distribution of velocity, temperature and moisture, allowing the study of different mitigation strategies for urban heat islands, by comparing different heat storage and heat removal mechanisms.

Under wet conditions, permeable pavements can give lower surface temperatures than impermeable pavements. The cooling provided by evaporation strongly depends on material properties, on the availability of moisture near the surface and on the evaporation 
rate. For the materials selected in this study, permeable pavements have a significantly longer first period compared to conventional concrete, which enters the second drying stage almost immediately after the end of the rain event. The duration of the first drying stage increases with decreasing material porosity due to reduced gravity effects, which prevent the water for being efficiently transported at the surface.

Albedo has a great influence on the pavement surface temperature. In wet conditions, evaporative cooling is more efficient on pavements presenting lower albedo, since they absorb more heat from the sun. However, this also implies a faster water evaporation and a shorter first drying period, compared to pavements presenting larger surface albedo. Pavements having higher albedo reflect more solar radiation to the other street canyon surfaces. This results in a slightly increase of surface temperature for windward and leeward facade. However, the effect of the reduced heat absorption on the street is always larger than reduced evaporative cooling effects and increased reflections. Overall, these results show that using combinations of high albedo and permeable pavements can potentially help to reduce urban surface temperatures, to reduce urban air temperatures and to mitigate urban heat islands.

\section{Acknowledgment}

This work is supported by the Swiss Competence Center for Energy Research project "Future Energy Efficient Buildings and Districts", CTI.1155002539.

\section{References}

Akbari, H., M. Pomerantz, and H. Taha (2001). Cool surfaces and shade trees to reduce energy use and improve air quality in urban areas. Solar energy $70(3)$, 295-310.

ASHRAE (2001). Ashrae fundamentals handbook 2001 (si edition). American Society of Heating, Refrigerating, and Air-Conditioning Engineers 31.

Brunetti, G., J. Simunek, and P. Piro (2016). A comprehensive numerical analysis of the hydraulic behavior of a permeable pavement. Journal of $\mathrm{Hy}$ drology 540, 1146-1161.

Carnielo, E. and M. Zinzi (2013). Optical and thermal characterisation of cool asphalts to mitigate urban temperatures and building cooling demand. Building and Environment 60, 56-65.

Defraeye, T. (2011). Convective Heat and Mass Transfer at Exterior Building Surfaces. Ph. D. thesis, KU Leuven.

Ferguson, B. K. (2005). Porous pavements. CRC Press.
Ferziger, J. H. and M. Peric (2012). Computational methods for fluid dynamics. Springer Science \& Business Media.

Fiala, D., G. Havenith, P. Bröde, B. Kampmann, and G. Jendritzky (2012). Utci-fiala multi-node model of human heat transfer and temperature regulation. International journal of biometeorology 56(3), 429441 .

Fwa, T., E. Lim, and K. Tan (2015). Comparison of permeability and clogging characteristics of porous asphalt and pervious concrete pavement materials. Transportation Research Record: Journal of the Transportation Research Board (2511), 72-80.

Hagentoft, C.-E., A. S. Kalagasidis, B. Adl-Zarrabi, S. Roels, J. Carmeliet, H. Hens, J. Grunewald, M. Funk, R. Becker, D. Shamir, et al. (2004). Assessment method of numerical prediction models for combined heat, air and moisture transfer in building components: benchmarks for onedimensional cases. Journal of thermal envelope and building science 27(4), 327-352.

Hassn, A., A. Chiarelli, A. Dawson, and A. Garcia (2016). Thermal properties of asphalt pavements under dry and wet conditions. Materials \& Design 91, 432-439.

Kevern, J. T., V. R. Schaefer, and K. Wang (2009). Temperature behavior of pervious concrete systems. Transportation Research Record 2098(1), 94-101.

Kubilay, A., D. Derome, and J. Carmeliet (2018). Coupling of physical phenomena in urban microclimate: A model integrating air flow, wind-driven rain, radiation and transport in building materials. Urban climate 24, 398-418.

Launder, B. E. and B. Sharma (1974). Application of the energy-dissipation model of turbulence to the calculation of flow near a spinning disc. Letters in heat and mass transfer 1(2), 131-137.

Li, H., J. T. Harvey, T. Holland, and M. Kayhanian (2013). The use of reflective and permeable pavements as a potential practice for heat island mitigation and stormwater management. Environmental Research Letters 8(1), 015023.

Meteonorm (2000). Global meteorological database for solar energy and applied climatology. Meteotest, Bern, Switzerland.

Moonen, P., T. Defraeye, V. Dorer, B. Blocken, and J. Carmeliet (2012). Urban physics: Effect of the micro-climate on comfort, health and energy demand. Frontiers of Architectural Research 1(3), 197-228. 
Murakami, S. (1993). Comparison of various turbulence models applied to a bluff body. In Computational Wind Engineering 1, pp. 21-36. Elsevier.

Saneinejad, S., P. Moonen, and J. Carmeliet (2014). Coupled cfd, radiation and porous media model for evaluating the micro-climate in an urban environment. Journal of Wind Engineering and Industrial Aerodynamics 128, 1-11.

Santamouris, M. (2013). Using cool pavements as a mitigation strategy to fight urban heat island. a review of the actual developments. Renewable and Sustainable Energy Reviews 26, 224-240.

Van Genuchten, M. T. (1980). A closed-form equation for predicting the hydraulic conductivity of unsaturated soils 1. Soil science society of America journal 44(5), 892-898. 